\title{
BIOTÉCNICAS REPRODUTIVAS: CAPTURA, EXAME ANDROLÓGICO, CONSERVAÇÃO DO EJACULADO E INSEMINAÇÃO ARTIFICIAL EM CANÍDEOS E FELÍDEOS SELVAGENS EM RISCO DE EXTINÇÃO
}

\author{
Luiza Isaias de Freitas ${ }^{1}$ \\ Renata Dos Santos Machado ${ }^{1}$
}

\begin{abstract}
RESUMO
Devido a acelerada redução no número de animais e consequente declínio na variabilidade genética, foi necessário estudar e aplicar biotécnicas de reprodução em animais silvestres, com a finalidade de reduzir o impacto sobre estas e diminuir o risco de extinção de diferentes espécies de canídeos e felídeos selvagens. O presente estudo, por metodologia qualitativa, por meio de revisão bibliográfica, realizou análise de estudos e dados existentes, com objetivo de elucidar e descrever os métodos de captura dos animais, o exame andrológico, meios de conservação do ejaculado e a inseminação artificial em canídeos e felídeos selvagens com fim de preservação das espécies ameaçadas de extinção.
\end{abstract}

Palavras-Chave: preservação, canídeos, felídeos, selvagens, reprodução.

\section{REPRODUCTIVE BIOTECHNIQUES: CAPTURE, ANDROLOGICAL EXAMINATION, EJACULATE CONSERVATION AND ARTIFICIAL INSEMINATION IN WILD DOGS OR FELIDS IN EXTINCTION RISK}

\begin{abstract}
Due to the accelerated reduction in the number of animals and the consequent decline in genetic variability, it was necessary to study and apply breeding biotechniques in wild animals, in order to reduce the impact on them and decrease the risk of extinction of different species of wild canids and felids. The present study, through qualitative methodology, through bibliographic review, carried out analysis of existing studies and data, with the objective of elucidating and describing the methods of capturing the animals, the andrological examination, means of preserving the ejaculate and artificial insemination canids and wild felids for the purpose of preserving endangered species.
\end{abstract}

Key words: preservation, canids, felids, wild, reproduction.

\section{BIOTECNICAS REPRODUCTIVAS: CAPTURA, EXAMEN ANDROLÓGICO, CONSERVACIÓN EYACULADA E INSEMINACIÓN ARTIFICIAL EN CÁNIDOS E FELINOS SILVESTRES EN RIESGO DE EXTINCIÓN}

\section{RESUMÉN}

Debido a la reducción acelerada del número de animales y la consecuente disminución de la variabilidad genética, fue necesario estudiar y aplicar biotecnologías de cría en animales salvajes, con el fin de reducir el impacto sobre ellos y disminuir el riesgo de extinción de diferentes especies de cánidos y felinos salvajes. El presente estudio, mediante metodología

\footnotetext{
${ }^{1}$ Graduanda em Medicina Veterinária da Universidade Federal de Santa Maria - *Correspondência: luizaifvet@gmail.com
} 
cualitativa, por revisión bibliográfica, realizó análisis de estudios y datos existentes, con el objetivo de dilucidar y describir los métodos de captura de los animales, el examen andrológico, los medios de preservación del eyaculado y la inseminación artificial en cánidos y felinos silvestres con el fin de preservar especies en peligro de extinción.

Palabras clave: preservación, cánidos, félinos, silvestres, reproducción.

\section{INTRODUÇÃO}

Estudos reprodutivos são muitas vezes associados apenas à produção animal, entretanto, se aplicam em diversas áreas, como a preservação de espécies ameaçadas. Em consequência da destruição do habitat natural, muitas espécies foram afetadas, onde o número de indivíduos de sua população ficou relativamente baixo, levando ao status de espécie ameaçada de extinção. A fim de diminuir o risco dessas espécies de serem extintas, estudos relativos à reprodução desses animais vêm sendo amplamente discutidos. Em canídeos e felídeos selvagens a aplicação de biotécnicas de reprodução tanto ex-situ e in-situ são consideradas meios de assegurar a permanência de um número razoável de exemplares e diversidade genética destes na natureza e em zoológicos e centros conservacionistas. Neste trabalho, buscamos por meio de uma revisão bibliográfica elucidar os meios de captura destes animais, o exame andrológico, a preservação do sêmen e inseminação artificial a fim de proporcionar a preservação de canídeos e felídeos selvagens e/ ou silvestres em risco de extinção.

\section{DESENVOLVIMENTO}

\section{Captura dos animais}

A captura de animais silvestres e selvagens com fins científicos ou de preservação deve ser bem planejada e elaborada. A contenção do animal deve oferecer segurança a ele a ao manipulador, evitando o estresse e o risco de ferimentos. A maior preocupação em relação ao animal é não causar lesões ou estresse excessivo, que acarreta em desequilíbrio homeostático e pode levar ao óbito imediato ou após até 48 horas da manipulação. A captura dos animais deve ser liberada pelo IBAMA após o envio de documentos comprobatórios necessários.

A captura dos animais, conforme Silva (1) se dá geralmente por atração do animal com alimento e armadilhas. Em algumas espécies a captura é feita com dardos anestésicos, entretanto além do custo da técnica o anestésico utilizado pode influenciar na coleta de sêmen via eletroejaculação. Além disso, a captura com uso de anestésicos necessita de 5 a 15 minutos para a sedação do animal, e o mesmo pode fugir ou se lesionar ou inclusive vir a óbito devido aos efeitos da anestesia. A captura dos animais, pode se dar por diferentes tipos de armadilhas, como com o auxílio de caixas (geralmente metálicas), currais, redes e trincheiras (buracos no solo) (1). Ademais, Araújo (2) acrescenta a captura de grandes felinos com armadilhas de laço.

Em relação a interferência dos fármacos utilizados na captura anestésica na eletroejaculação, Silva (3) relata que a xilazina, um agonista alfa-2-adrenérgico pode alterar a concentração espermática, e quando associada a outros fármacos pode promover aumento na ejaculação retrógrada (para a vesícula urinária), ou ainda, apresenta maiores chances de contaminação seminal com a urina. Ainda, em felinos, a medetomidina promove liberação de espermatozóides na uretra (4), sendo por si só utilizada em método de coleta farmacológica de 
sêmen. Além disso, deve-se levar em consideração o tempo de início de ação (indução) do fármaco, janela que pode chegar a 15 minutos, podendo o animal fugir e sofrer danos físicos.

\section{Exame andrológico}

O exame andrológico é de fundamental importância para caracterizar o potencial reprodutivo dos animais, realizar as técnicas de aproveitamento de sêmen, e avaliar possíveis causas de infertilidade de machos silvestres. Ele deve ser executado por um veterinário capacitado, com conhecimento de animais selvagens ou silvestres (5). Para a realização do mesmo, inicialmente deve-se coletar as informações de identificação do animal, constatando o histórico, caso houver, e realizar a anamnese. Normalmente é necessária a realização de contenção química do animal para manipulação do mesmo para procedimentos de avaliação física.

\section{Exame andrológico: Exame físico}

No exame físico geral, devem ser avaliados a condição corporal, parâmetros vitais, assim como realizar exame de palpação dos linfonodos, exame do aparelho locomotor, exame bucal, aferição de temperatura e por fim, avaliação das condições gerais do animal, como comportamento, estado de saúde, envelhecimento e pelagem $(4,5)$. Todos esses fatores, se estiverem comprometidos, podem afetar a função reprodutiva do animal (6).

No exame físico específico, é realizada a avaliação do sistema reprodutor do animal. Avalia-se na bolsa testicular, o epidídimo e os testículos, analisando a simetria, posição e localização dos mesmos. Observa-se a consistência (flácido, duro), mensurando o comprimento e a largura, assim como circunferência escrotal. Avalia-se, também, a sensibilidade dolorosa, a temperatura, presença de sinais de hematoma, feridas ou outras alterações. O pênis e o prepúcio devem ser examinados quanto à morfologia, presença de secreção, exposição e retração peniana e outras alterações (6). Nos canídeos, deve-se notar a presença do osso peniano, e nos felídeos, observa-se a presença das espículas penianas, esse último é indicativo de produção de testosterona pelo animal (7). No exame físico específico interno, avalia-se a próstata (única glândula acessória presente nos felídeos), ampolas, glândulas bulbouretrais (6).

\section{Exame andrológico: coleta do ejaculado}

Uma técnica de baixo custo que pode ser empregada é a vagina artificial. Ribeiro et al. (8) relatam que esta devido necessitar de treinamento do animal por pelo menos duas semanas se torna pouco prática, ademais, acrescentam que esta é bem sucedida somente em até $70 \%$ dos casos. Catardo et al. (9) relatam que em animais selvagens e silvestres de grande porte, a técnica pode oferecer riscos às pessoas envolvidas na coleta. Em contrapartida, este meio de coleta proporciona um ejaculado de excelente qualidade para a análise, além de poder ser utilizado diariamente ou em intervalos curtos, ao contrário da eletroejaculação. Ribeiro et al. (8) acrescenta que coletas duplas (consecutivas) por 24,48 e $72 \mathrm{~h}$ não afetam a qualidade seminal por até 10 dias de coletas diárias.

Basicamente a vagina artificial pode ser montada com um tubo revestido e com bulbo de borracha e um copo coletor, existem kits prontos disponíveis no mercado. Ainda, é possível que o macho faça a monta em uma fêmea no cio, e o sêmen coletado com a vagina artificial acoplada no pênis com o apoio do polegar e dedo indicador estimulando a ejaculação 
(8). Moreira (10) relata que a coleta via vagina artificial possui menor volume e maior concentração espermática que a coleta por eletroejaculação. Ademais, Catardo et al. (9) acrescentam que esta técnica é mais utilizada em "colônias de pesquisa quando há necessidade de colheitas seriadas". Paz (11) relata que esse método é mais utilizado em canídeos, relatando a colheita de sêmen de lobo guará por esta técnica, utilizando recompensas com petiscos de carne para o condicionamento do animal.

Principalmente em felinos, pode ser aplicada a coleta farmacológica, também conhecida por cateterização uretral (4). Fármacos sedativos alfa-adrenérgicos como a medetomidina ao proporcionarem a anestesia geral no animal promovem a liberação de sêmen na uretra, apesar de não promover ereção ou ejaculação $(4,8)$, dispensando o eletroejaculador e mantendo boa qualidade do sêmen. Conforme Ribeiro et. al (8) é uma técnica promissora e eficaz em felinos.

Ao estimular os receptores alfa-2-adrenérgicos ocorre a contração dos ductos deferentes, liberando o sêmen na uretra. Moreira (10), relata que em onças utilizando protocolo anestésico de medetomidina e cetamina após 20 e 40 minutos da indução anestésica foi possível realizar a coleta de sêmen de todos os animais por sonda uretral estéril. Ribeiro et. al (8) descrevem que, em estudo realizado em felinos selvagens uma única coleta com cateter uretral imediatamente após o início da anestesia leva a um ejaculado de boa qualidade e com pouca chance de danificar a uretra. Conforme Ribeiro et. al (8), a coleta se dá com cateter urinário para gatos, com tamanho adequado ao animal, este é introduzido na uretra até a região dilatada do sêmen, sendo a coleta pelo lúmen do cateter por forças capilares. Este método é de baixo custo e não necessita de treinamento do animal como no uso da vagina artificial, ademais, com a existência de reversores químicos aos anestésicos utilizados, apesar da existência de efeitos colaterais (principalmente cardiovasculares), este método é favorecido apesar do pouco volume de ejaculado obtido.

Ribeiro et. al (8) relatam que a coleta também pode ser realizada por lavagem ou aspiração do epidídimo em animais submetidos a orquiectomia ou que foram a óbito, ademais, nestes mesmos casos, Paz (11) relata a coleta de sêmen da cauda do epidídimo. Ainda, conforme Moreira (10), é possível obter sêmen por lavado vaginal após a cópula, todavia a prática deste método em felídeos selvagens é baixa.

Todavia, a coleta do sêmen se dá geralmente via eletroejaculação transretal, por meio de uso de diferentes tipos de probes (10). Silva (3) descreve que este é o método mais utilizado em animais silvestres. Em felídeos, conforme Moreira (10), o protocolo da eletroejaculação mais usual consiste em "80 estímulos elétricos de 2 a $5 \mathrm{~V}$ aplicados em três séries, sendo 30 de 2 a 4 V, 30 de 3 a 5 V; e 20 estímulos de 4 e 5 V".

Além do protocolo, o tipo de probe utilizada, assim como o protocolo anestésico podem influenciar na coleta e na qualidade do sêmen quando utilizada a eletroejaculação. Moreira (10), relata que "alguns estudos reportaram os efeitos da voltagem, coleta sequencial, coleta durante longo período e fluxo retrógrado nas características seminais", todavia, ressalta que "não altera a capacidade ejaculatória ou causa efeitos nocivos aos machos". Ademais, o equipamento é oneroso e existe o risco da urina contaminar o ejaculado, além de mesmo sob protocolo anestésico geral os animais demonstram contrações musculares. Em contrapartida, a técnica tem como vantagens que animais não aptos a monta natural (por razões físicas ou psicológicas) podem ter sêmen coletado, além de não necessitar de fêmea no cio ou treinamento do macho, podendo ser utilizada em todo o macho que possa passar por anestesia de forma segura. Catardo et al. (9) descrevem que existe uma considerável variação de volume de ejaculado e espermatozoides no sêmen entre animais da mesma espécie e de espécies diferentes quando utilizado a eletroejaculação. Moreira (10), ainda relata que, bom base na experiência profissional, observou-se benefícios deste método em machos que 
estavam há longo período em repouso sexual, como melhora na qualidade seminal a partir da segunda coleta, estímulo da espermatogênese além de promover a renovação espermática. Fukui et al. (12) relatam em um tigre siberiano o aumento do número de espermatozóides móveis após a eletroejaculação.

Em relação ao número de espermatozóides coletados via estímulos elétricos, quanto maior a voltagem maior será o número destes, além de em conjunto aumentar as chances de contaminação com urina, principalmente em canídeos e com estímulos de altas voltagens (acima de $6 \mathrm{~V}$ ), tal contaminação é detectada pelas características do ejaculado, como volume, $\mathrm{pH}$, coloração e aspecto, a contaminação por urina pode levar a perda rápida da motilidade espermática. Paz (11), informa que há relato de contaminação por urina utilizando a eletroejaculação em lobo-guará (Crysocyon brachyurus) e Silva (3) relata em gato-do-matopequeno. Ademais, a fim de evitar a contaminação deve-se, conforme Silva (3) induzir a micção antes da indução da ejaculação, podendo fazer uso da cateterização uretral.

É válido ressaltar que, conforme relatado por Moreira (4), o $\mathrm{pH}$ seminal coletado por eletroejaculação tende a ser maior que o coletado via vagina artificial por exemplo, segundo o mesmo autor, tal fato pode ocorrer devido ao estímulo elétrico que leva a maior participação das glândulas sexuais acessórias.

Por fim, o equipamento utilizado assim como as probes devem ser adaptados às espécies e diferentes portes dos animais, além disso, Catardo et al. (9) relatam em relação aos protocolos anestésicos utilizados que os mais descritos são a cetamina com ou sem associação com a medetomidina e associações de zolazepam, tiletamina e morfina, já Silva (3) relata que a xilazina em associação com a cetamina teve sucesso em leopardos (Panthera pardus) e outros animais silvestres como quatis, veados e lhamas.

\section{Exame andrológico: Avaliação do ejaculado}

A avaliação do ejaculado deve ser realizada imediatamente após a colheita, pelo espermograma. Neste é avaliado macroscopicamente o volume, o aspecto, odor e a coloração, e microscopicamente a motilidade, vigor, concentração e a morfologia espermática. Além disso, é avaliado fisicamente o $\mathrm{pH}$, e também, faz-se a determinação da integridade da membrana espermática e acrossomal. $\mathrm{O}$ aspecto pode variar de cremoso, leitoso, seroso até aquoso, dependendo da concentração espermática. O odor é peculiar do material, ou seja, Sui generis (de clara de ovo). A cor pode variar de acordo com o teor de riboflavina na dieta, indo de branco a marfim ou amarelado. A produção espermática é diretamente influenciada pela idade, tamanho testicular e da próstata, frequência de coleta, repouso sexual e estimulação $(4,6)$.

\section{Conservação do ejaculado}

Em animais silvestres e selvagens, principalmente em espécies ameaçadas, a preservação do sêmen é um importante recurso para a preservação e manutenção da espécie. Moreira (4) descreve que o método mais utilizado é a criopreservação, geralmente em meios tendo a gema de ovo como base, entretanto, destaca que este tipo de base pode ocasionar em variações entre lotes produzidos, contaminação por micro-organismos e está passível de restrições de transporte principalmente se este é internacional. Moreira (4), ainda relata que, em sua prática preconiza utilizar bases comerciais de preservação, com maior controle de qualidade dos ingredientes, garantia antimicrobiana ou utilização de ovos com selo de SPF, livre de patógenos. A fim de investigar outra alternativa de meio (base) para a criopreservação, Vansandt et al. (13) testaram como base a lecitina de soja, em comparação a gema de ovo na 
criopreservação de sêmen de gato-de-pallas (Otocolobus manul) e gato-pescador (Prionailurus viverrinus) onde os resultados foram semelhantes na clivagem embrionária demonstrando a lecitina de soja como alternativa a utilização da gema de ovo nessas espécies de felinos selvagens.

Moreira (4) ressalta que a utilização de meios base livres de proteína animal, como meio químicos definidos representam um avanço na qualidade e biosseguridade na preservação do sêmen, preservação importantíssima em casos de animais ameaçados. Ademais, Kaneko et al. (14) acrescentam um método mais moderno, que permite maior tempo de armazenagem e que não necessita de nitrogênio líquido e temperaturas extremamente baixas, pode ser armazenado em refrigeradores a $4^{\circ} \mathrm{C}$, chamado de liofilização. Este método consiste na liofilização dos espermatozóides em solução contendo $10 \mathrm{mM}$ Tris e $1 \mathrm{mM}$ EDTA, todavia ressalta que os relatos desta técnica são preliminares e demandam mais estudos em demais espécies, sendo já demonstrada a eficácia de viabilidade espermática após este método em Onças-pintadas. Conforme Paz (11), em carnívoros o método de criopreservação mais usual é o que utiliza glicerol como crioprotetor, e ainda acrescenta que há diferentes métodos, diluidores e crioprotetores sendo testados a fim de aumentar a taxa de sobrevivência espermática após o descongelamento.

Paz (11) ressalta a importância da correta identificação dos materiais criopreservados, contendo todas as características do animal, data, local de captura e demais informações relevantes, uma vez que a utilização destes depende da correta identificação. Moreira (10) ainda acrescenta que o sucesso destas técnicas em felídeos ainda é relativamente baixo, havendo a perda de motilidade dos espermatozoides após o descongelamento, podendo haver recuperação ou não na motilidade destes.

\section{Inseminação artificial}

No teste de ação avalia-se a libido do animal, ou seja, vontade de copular ou não. A baixa libido pode indicar um problema hormonal, assim como também um problema comportamental. Canídeos e felídeos necessitam de estímulos visuais, auditivos, e principalmente de feromônios, odores lançados pelas fêmeas em estro e proestro. Esses feromônios podem ter origem de esteróides fecais ou urinários $(4,11)$. Sabendo disso, pode-se utilizar de técnicas de estimulação para realizar a coleta do sêmen, e posteriormente, induzir a fêmea ao estro para realização da inseminação artificial (5).

De acordo com o estudo de Tajima et al. (15), foi possível realizar com sucesso a inseminação artificial intrauterina seguido de obtenção do filhote saudável de uma fêmea de Leopardo-de-amur (Pionailurus bengalensis eutilura) pela primeira vez no Japão, a partir de administração de gonadotrofinas coriônicas humana e equina (hCG e eCG) no animal em anestro. Porém, segundo estudo de MOREIRA (10):

Embora algum progresso tenha sido feito, fatores limitantes, como a grande variabilidade na resposta à utilização de produtos altamente heterólogos como o eCG e o hCG, têm dificultado a obtenção de melhores resultados na estimulação da atividade ovariana. [...] Investigações recentes, com a utilização de progestágenos no pré-tratamento com o objetivo de melhorar a resposta ovariana, têm fornecido resultados promissores em várias espécies de felídeos. O desenvolvimento desses protocolos, associados à criopreservação de sêmen e embriões e ao desenvolvimento de gonadotropinas especificas para felídeos, aumentará a utilidade das técnicas de reprodução assistida para a conservação dessas espécies. 
Desta forma, é necessário o conhecimento da fisiologia reprodutiva do animal em questão, seja sobre o ciclo estral, hormônios envolvidos e duração da atividade ovariana da fêmea, somado a utilização de estimulantes para indução do estro e a ovulação.

No caso da fisiologia reprodutiva de fêmeas de felídeos, assim como as gatas domésticas, são classificadas como poliéstricas estacionais, apresentam ciclo estral associado ao fotoperíodo positivo, com duração média de 2 a 3 semanas, sendo a fase de estro com duração de 2 a 19 dias, caracterizado pela receptividade a monta, pico de secreção de estradiol, e sinais comportamentais como lordose, desvio lateral da cauda, vocalização, rolamento do corpo e atração do macho para coito. São animais de ovulação induzida, podendo desencadear ovulação com estimulação mecânica ou hormonal, sendo esse último pela utilização de hormônios exógenos como o FSH (hormônio folículo estimulante) ou eCG (gonadotrofina coriônica equina) e a maturação final dos folículos e ovulação podem ser induzidos com a aplicação de GnRH, hCG (gonadotrofina coriônica humana) ou LH (hormônio luteinizante) (16).

$\mathrm{Na}$ fisiologia de fêmeas canídeas, assim como os caninos domésticos, são espécies monoéstricas não-estacionais, apresentando ciclos estrais longos (17). Tem como sinais visíveis de cio o aparecimento de corrimento vaginal rosados ou sanguinolentos, inchaço da vulva e aceitação do macho para monta (11). Para indução do estro, é utilizado deslorelina (agonista de GnRH), LH recombinante, FSH, eCG e hCG intravenosos (17,18). Para monitoramento da progressão do ciclo estral de fêmeas de canídeos selvagens, é utilizado como método de rotina a colpocitologia, onde esfregaços vaginais são coletados semanalmente para diagnóstico e acompanhamento das fases do ciclo reprodutivo (11).

Para realização da inseminação artificial, é necessária a prévia avaliação do sêmen após colheita, descongelamento do mesmo caso conservado em método de criopreservação, avaliação da integridade do mesmo e deve-se fazer cálculo da quantidade de espermatozóides por inseminação. Após, deve-se fazer a preparação das fêmeas para inseminação artificial, observando comportamento, realizando exames de citologia vaginal e ultrassonografia. Assim, pode-se realizar a indução da ovulação, e finalmente, o procedimento de inseminação artificial (19).

O procedimento de inseminação artificial pode ser realizado por dois métodos: inseminação intravaginal (IAIV) ou intrauterina (IAIU). Em qualquer método, os animais devem ser submetidos a anestesia para contenção total, segura e sem estresse. Para o método de inseminação intra-vaginal é utilizada uma sonda uretral, onde, introduzida na vagina da fêmea, é depositado lentamente o sêmen previamente calculado, e após a inseminação, a permanência do animal em decúbito dorsal com posterior elevado de 15 a 20 minutos para evitar o refluxo do sêmen (19). O método de inseminação artificial intrauterina é realizado em laparoscopia por vídeo, consistindo na deposição do sêmen diretamente no interior do corno uterino, pela canulação de agulha estéril com cateter, inserida pela cavidade abdominal. Nesse método, é necessária sedação com anestesia inalatória (11).

Dos métodos de inseminação artificial, a inseminação intrauterina é considerada o método menos invasivo de inseminação artificial. $\mathrm{O}$ método intravaginal apresenta resultados inferiores comparados ao método de IAIU, pois a anestesia compromete o transporte do sêmen em fêmeas inseminadas por método não cirúrgico, além do comprometimento devido utilização de sêmen congelado de baixa qualidade após descongelamento, o que teria maior taxa de sucesso se realizada com a IAIU $(11,18)$.

Por fim, exames complementares como ultrassonografia e laboratoriais podem ser de extrema importância no auxílio do diagnóstico final de prenhez, monitoramento e saúde, tanto da fêmea como do filhote.

\section{CONSIDERAÇÕES FINAIS}

Freitas LI, Machado RS. Biotécnicas reprodutivas: Captura, exame andrológico, conservação do ejaculado e inseminação artificial em canídeos e felídeos selvagens em risco de extinção. Vet. e Zootec. 2021; v28: 001-009. 
Desta forma, concluímos que a aplicação de biotécnicas reprodutivas em canídeos e felídeos selvagens ou silvestres é uma necessidade emergente, a fim de preservar as espécies que estão em risco de extinção. Sendo assim, deve-se empregar formas corretas e seguras de captura dos animais, tanto para o animal tanto para a equipe envolvida, sendo uma das técnicas de captura via anestésicos. Sendo assim, os anestésicos utilizados na captura devem ser escolhidos de forma que garantam a segurança anestésica ao animal, possuam rápido início de ação, permitam a realização do exame andrológico físico e não interfiram nos meios de coleta do ejaculado, modificando as características seminais na análise destas principalmente se a coleta for feita via estímulos elétricos. Ademais, a utilização de inseminação artificial (IA) nestes animais é um método eficaz de reprodução e de grande importância na produção de indivíduos geneticamente viáveis, tendo em vista a diminuição da variabilidade genética decorrente da redução da população destes animais. A IA pode ser realizada cirurgicamente (IAIU) ou não cirurgicamente (IAIV), onde, apesar de a inseminação artificial intrauterina ser considerada método cirúrgico, é menos invasiva e possui maiores taxas de sucesso na fertilização, sendo esta a opção com melhor aproveitamento espermático. Ademais, em animais silvestres e selvagens está é realizada geralmente via laparoscópica, para diminuir a invasão cirúrgica. Por fim, devemos ressaltar que para a realização destes procedimentos é necessária uma equipe capacitada, com médicos veterinários treinados e com conhecimentos sobre cada espécie de animal a ser estudada, a fim de realizar uma correta e segura contenção, avaliação, sedação e posterior monitoramento do animal, além da correta execução e escolha de exames andrológicos, ginecológicos e ambulatoriais e de procedimentos cirúrgicos envolvidos.

\section{REFERÊNCIAS}

1. Silva LCS. Contenção e Captura de Animais Selvagens. Curso de contenção e captura de animais selvagens [Internet]. Jandaia: Centro Científico Conhecer, 2011 [citado 10 Jan 2021]. $\quad$ p. 1-62. Disponível em: http://www.conhecer.org.br/download/CONTENCAO\%20E\%20CAPTURA\%20DE\%20A NIMAIS $\% 20$ SELVAGENS/Curso $\% 20$ contencao $\% 20 \mathrm{e} \% 20$ captura $\% 20 \mathrm{de} \% 20$ animais $\% 20$ selvagens.pdf

2. Araújo GR. Coleta farmacológica e criopreservação de sêmen de grandes felinos mantidos em cativeiro e capturados em vida livre com o uso de armadilhas de laço. [tese]. Viçosa: Universidade Federal de Viçosa; 2016.

3. Silva CDOC. Biotécnicas da reprodução aplicadas à conservação de mamíferos silvestres [trabalho de conclusão de curso]. Brasília: Faculdade de Agronomia e Medicina Veterinária, Universidade de Brasília; 2017.

4. Moreira N. Técnicas reprodutivas para a conservação de felídeos silvestres. Rev Bras Reprod Anim. 2017;41(1):116-20.

5. Echeverri AML, Henry M. Andrologia veterinária básica: curso de andrologia veterinária básica. Belo Horizonte: Universidade Federal de Minas Gerais; 2013.

6. Feitosa. Semiologia veterinária: a arte do diagnóstico. São Paulo: Roca; 2014. 
7. Erdmann RH, Juvenal JC, Moraes W, Cubas P, Carvalho A, Moreira N. Exame reprodutivo em Gato-do-mato-pequeno (Leopardus tigrinus Schreber, 1775). Arch Vet Sci. 2006;10(2):75-9.

8. Ribeiro RN, Almeida ARG, Martinez AC. Métodos de coleta de sêmen em felídeos. Enciclopédia Biosfera. 2019;16(29):1-15.

9. Catardo FA, Scolari S, Más-Rosa S. Técnicas reprodutivas, criopreservação espermática e coleta de sêmen em felinos selvagens visando à conservação - Revisão bibliográfica. Rev Cient Eletrônica Med Vet. 2018;10(30):1-11.

10. Moreira N. Exame andrológico e criopreservação de sêmen em felídeos selvagens. Rev Bras Reprod Anim. 2017;41(1):312-5.

11. Paz RCR. Reprodução assistida em canídeos e procionídeos neotropicais. Rev Bras Reprod Anim. 2015;39(1):77-82.

12. Fukui D, Nagano M, Nakamura R, Bando G, Nakata S, Kosuge M, et al. The effects of frequent electroejaculation on the semen characteristics of a captive Siberian Tiger (Panthera tigris altaica). J Reprod Dev. 2013;59(5):491-5.

13. Vansandt LM, Bateman HL, Newsom J, Swansos W, Ansandt LM, et al. Getting the yolk out: the use of a soy lecithin-based cryomedium for semen banking in the Pallas' cat and fishing cat. Reprod Fertil Dev. 2017;29(1):165-6.

14. Kaneko T, Ito H, Sakamoto H, Onuma M, Inoue-Murayama M. Sperm preservation by freeze-drying for the conservation of wild animals. PloS One. 2014;9(11):e113381.

15. Tajima H, Yoshizawa M, Sasaki S, Yamamoto F, Narushima E, Tsutsui T, et al. Intrauterine insemination with fresh semen in Amur leopard cat (Prionailurus bengalensis eutilura) during non-breeding season. J Vet Med Sci. 2017;79(1):92-9.

16. Villaverde AISB, Lopes MD. Inseminação artificial em gatos domésticos utilizando sêmen criopreservado. Rev Bras Reprod Anim. 2007;31(1):77-83.

17. Peixoto GCX, Pereira AF, Silva AR. Indução e sincronização de estro em mamíferos selvagens - uma revisão. Rev Bras Reprod Anim. 2016;40(1):3-7.

18. Montanha FP, Demori MVA. Inseminação artificial em cães - revisão. Rev Cient Eletrônica Med Vet. 2013;11(20):1-7.

19. Villaverde AISB. Comparação entre dois métodos de inseminação artificial utilizando sêmen congelado em gatos domésticos (Felis catus) [dissertação]. Botucatu: Faculdade de Medicina Veterinária e Zootecnia, Universidade Estadual Paulista; 2007.

Recebido em: 25/01/2021 Aceito em: 29/09/2021 